\title{
Correlation of digital chest radiograph parameters with pulmonary function test and bode index for diagnosis and prognostication in Indian COPD patients
}

\begin{abstract}
Background: The spectrum of various chest radiographic indices which are used to correlate with Pulmonary function testing (PFT) and BODE index, are comprehensive from the previous studies. No previous literature has, however, assessed the threshold values for quantitative chest radiography (CXR) indices of Chronic Obstructive Pulmonary Disease (COPD) in Indian population
\end{abstract}

\begin{abstract}
Aim: Correlate the various quantitative and qualitative CXR indices of Obstructive Pulmonary Disease (COPD) with Pulmonary function testing (PFT) and BODE index. Derive the threshold values for quantitative chest radiography (CXR) indices of chronic obstructive pulmonary disease (COPD), for Indian population.
\end{abstract}

Study design \& Method: In this descriptive cross sectional study, patients who have obstructive pattern on spirometry were retrospectively selected, if they had a CXR done within 3 weeks. A control group with normal PFT was also selected. 145 cases and 78 controls were included in the study. Radiologists who were blinded to PFT results, independently evaluated CXR for various quantitative and qualitative parameters.

Results: Statistical correlation (Independent T test, Pearson's correlation coefficient) of various CXR parameters with PFT and BODE index was done. Among various qualitative parameters, alteration of vascular pattern, prominent intercostal muscle slips, increased lucency in lung parenchyma, presence of bulla showed correlation with PFT and BODE index. Among quantitative parameters, height of hemi diaphragm showed positive correlation and height of lung, number of posterior ribs and cardiothoracic ratio showed negative correlation with PFT and BODE index.

Conclusion: By using both quantitative and qualitative parameters in CXR, we can predict the presence, severity and prognosis of COPD. Derived threshold values for parameters like height of lung in Indian population are found to be lower than Western population.
Volume 5 Issue I - 2018

\author{
Vimala LR,' Gibikote S,' Christopher DJ,' Irodi \\ A,' Rajan $M,{ }^{2}$ Ramasami $P^{3}$ \\ 'Department of Radiology, Christian Medical College, India \\ 2Department of Pulmonary medicine, Christian medical college, \\ India \\ ${ }^{3}$ Department of Biostatistics, Christian Medical College, India
}

Correspondence: Leena Robinson Vimala, Department of Radiology, Christian Medical College, Vellore, India, Email leenarv76@gmail.com

Received: November 13, 2017 | Published: January 09, 2018

Keywords: quantitative parameters, pulmonary function test, BODE index, CXR

Abbreviations: PFT, pulmonary function testing; COPD, chronic obstructive pulmonary disease; CXR, chest radiography

\section{Introduction}

Chronic obstructive pulmonary disease (COPD) is one of the leading causes of morbidity and mortality worldwide. COPD was under diagnosed in India, but is now recognized in 4-10 per cent of adult male population of India and several other Asian countries. ${ }^{1}$ Spirometry is the accepted and standard for the diagnosis and assessment of severity of COPD. BODE index is a multidimensional grading system that assesses the respiratory and systemic expressions of COPD that would better categorize and predict outcome in these patients. It uses various clinical and physiological variables like bodymass index (B), the degree of airflow obstruction (O) dyspnoea (D), and exercise capacity (E) as assessed by the six-minute-walk test. ${ }^{2,3}$

Studies done in the past have provided conflicting results with regard to the role of radiographic evaluation of COPD. ${ }^{4,5}$ With the advent of digital radiography, there is significant improvement in the dynamic range and exposure latitude which has improved the quality of the chest radiograph, thereby increasing the rate of detection of various airway diseases. Various post processing tools [inversion of image, magnification, contrast adjustment etc.] are available in the picture archiving communication system [PACS] which further improve the image interpretation capabilities. Little has been done to study the ability of digital radiography to diagnose or quantify COPD when the patient is subjected to chest radiograph prior to evaluation with PFT or when COPD features are incidentally identified during routine radiographic reporting. This study was designed to correlate the various quantitative and qualitative indices of COPD in the postero-anterior CXR with pulmonary function test parameters and BODE index and to derive at the threshold values for quantitative CXR indices of COPD, for the Indian population.

\section{Methods}

The study was approved by the institutional research and ethics committee. The study was conducted in the Departments of Radiology and Pulmonary Medicine in a tertiary referral hospital 
in South India, which caters to patients from several states of the country. In this descriptive cross sectional study, consecutive patients with a provisional diagnosis of COPD who have obstructive pattern on spirometry were retrospectively selected from the pulmonary function lab database, if they had a chest radiograph within the past 3 weeks, during the period of October to June 2009. Patients with bronchodilator reversibility of $12 \%$ and $200 \mathrm{ml}$ or more, were excluded. A comparative group was chosen also from consecutive patients who were referred for pulmonary function tests, with no previous diagnosis of lung disease and had normal spirometry if they also had chest radiographs within 3 weeks of the PFT and 1 control was chosen for every 2 cases. The hospital identification numbers of the cases and controls were handed over to the radiologist investigator, who was blinded to the clinical diagnosis and the PFT results.

The pulmonary function test was performed in Jaeger master screen PFT system. The variables used for comparison are post dilator FVC, FEV1, FEV1/FVC, PEF, MMEF, DLCO, DLCO/Va, TLC, RV/TLC\%predicted. The cases were categorised as per GOLD classification, ${ }^{6}$ into normal, mild, moderate, severe and very severe on the basis of spirometry. Diffusion lung capacity, total lung capacity, residual volume were additionally done in a subgroup of patients. Exercise capacity test parameters like distance saturation product (DSP), 6 minute walk distance (6MWT) and BODE index were also performed in a subgroup of patients.

The radiologist obtained the necessary information from the radiographs and entered it in the case report form. Posteroanterior CXRs were performed either in GE DEFINIUM 6000 system [Direct digital radiography unit] or POLYDOROS LX 50 Multipulse $800 \mathrm{~mA}$ system [Computed radiography, cassettes were being read by AGFA Computed Radiography system] using high KV technique, at a standard $180 \mathrm{~cm}$ FFD, with the patient being in upright position and holding breath at full inspiration. Both quantitative and qualitative features were evaluated in the CXR.

The qualitative parameters used were:

a. Presence of prominent intercostal slips [Prom slips].

b. Visualisation of anterior junction line [AJL] (Figure 1).

c. Visualisation of posterior junction line [PJL] (Figure 1).

d. Presence of bulla (Figure2).

e. Alteration of normal vascular pattern assessed in 4 quadrants of the lung [Vas alt RTUP, Vas alt RTLP, Vas Alt LTUP, Vas Alt LTLP] - disorganised branching pattern often associated with reduction in vascularity ${ }^{\top}$ (Figure 2).

f. Presence of increased lucency - diffuse/focal [Inc Lucency] (Figure 2).

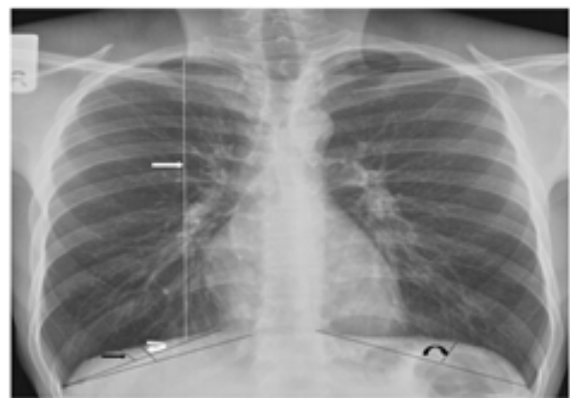

Figure I Chest radiograph PA view shows visualisation of anterior junction line (straight black arrow) and posterior junction line ( straight black arrow).

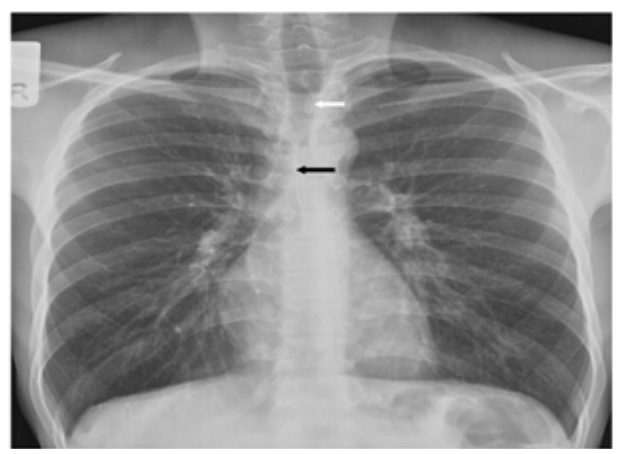

Figure 2 Chest radiograph PA view demonstrates presence of bulla (black asterix), alteration of normal vascular pattern assessed in right upper half (curved white arrow), presence of focal increased lucency (straight white arrow).

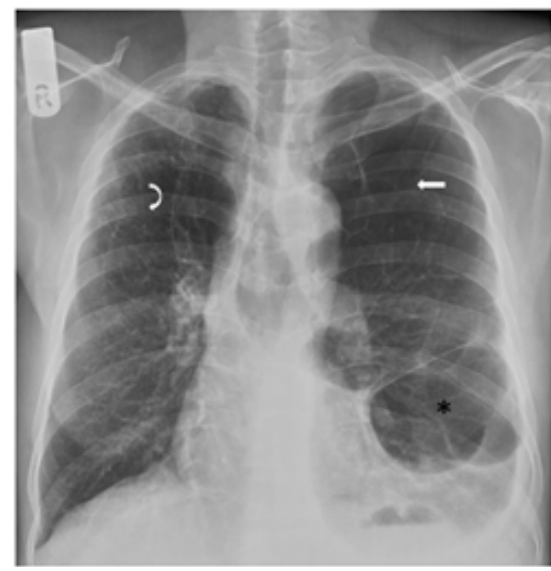

Figure 3 Chest radiograph PA view demonstrates the height of right hemidiaphragm (curved white arrow) and left hemidiaphragm (curved black arrow) measured using vertebrophrenic junction as medial endpoint. Height of right hemidiaphragm measured using cardiophrenic junction is shown in straight black arrows. Height of the right lung is shown in straight white arrow.

The quantitative parameters used were:

I. Height of right and left hemidiaphragm- the perpendicular distance between the diaphragmatic peak and the line connecting lateral and medial ends of the hemidiaphragm is measured. RTVP and LTVP represent the height of right and left hemidiaphragm measured using vertebrophrenic junction as medial endpoint respectively. RTCP represents height of right hemidiaphragm measured using cardiophrenic junction as the medial endpoint (Figure 3).

II. Height of the right lung - a perpendicular line drawn from the apex of the lung to a horizontal line drawn through the highest point of the right hemidiaphragm (Figure3).

III. Level of diaphragm - number of anterior ends of ribs seen at the mid-clavicular line [ANT MID] and at the costophrenic angle [ANT LAT], number of posterior ribs at the mid-clavicular line [POST].

IV. Cardiothoracic ratio - ratio of maximum transverse cardiac diameter to the maximum inner thoracic diameter[CTR].

$\mathrm{V}$. Ratio of the transverse diameter of the trachea taken at $1 \mathrm{~cm}$ above the aortic knuckle to that taken at the level of lung apex[COR DIA]. 
These radiologic data were correlated with the spirometric parameters. Those who had data for 6 minute walk test had correlations done of the measured variables and BODE index with the chest radiography indices.

\section{Results}

A total of 223 patients were included in the study; 145 of them were cases and 78 were controls. Of these, 184 were males and 39 were females. Smokers in the cases and control groups were 98 $(67 \%)$ and $26(33 \%)$ respectively. The GOLD stage of the disease was tabulated (Table 1). Of the 145 cases, there were 41 mild, 54 moderate, 29 severe and 21 very severe cases of COPD based on
GOLD spirometric classification. The mean, standard deviation and range of the spirometry, diffusion lung capacity and exercise capacity parameters for cases and controls are given in Table 2. The mean, standard deviation and range of the age, height, weight, and various quantitative parameters of CXR in COPD for the cases and controls are given in Table 3. Using one way Anova test, significant difference was found between the cases and controls in PFT and Bode indices. There was significant difference between the cases and controls in the demographic characteristics except in the height of the patients, no: of ribs seen anteriorly and cardiothoracic ratio. A subgroup of 40 patients had undergone 6 minute walk test.

Table I GOLD stage of the cases

\begin{tabular}{ll}
\hline Mild & 41 \\
\hline Moderate & 54 \\
Severe & 29 \\
Very severe & 21
\end{tabular}

Table 2 Characteristics of pulmonary function test, BODE index, exercise capacity parameters of cases and controls

\begin{tabular}{lll}
\hline Variables & Cases Mean \pm SD (Range) & Controls Mean \pm SD (Range) \\
\hline FVC & $2.62 \pm 0.87(0.97-4.39)$ & $2.98 \pm 0.91(0.99-5.23)$ \\
FEVI & $1.81 \pm 0.89(0.42-3.95)$ & $2.16 \pm 0.92(0.24-4.79)$ \\
FEVI/FVC ratio & $66.78 \pm 23.26(29-191)$ & $71.96 \pm 31(22-384)$ \\
PEFR & $5.6 \pm 2.82(0.8-11.47)$ & $6.57 \pm 2.57(0.37-12.73)$ \\
MMEF & $0.79(0.1-8.22)$ & $1.31(0-8.08)$ \\
DLCo & $5.81 \pm 3.2(0.96-13.07)$ & $7.37 \pm 3.75(2.65-11.27)$ \\
DLCo/Va & $1.69 \pm 0.84(0.46-5.37)$ & $1.91 \pm 0.77(0.95-3.14)$ \\
TLC & $4.28 \pm 0.85(2.69-6.63)$ & $4.73 \pm 0.68(3.86-5.79)$ \\
RV/TLC & $112.96 \pm 28.22(49-184)$ & $130.92 \pm 39.8(79.5-189)$ \\
Dist. Saturation & $372.87 \pm 109.09(|1| 6.4-616)$ & $393.58 \pm 104.83(266-576)$ \\
Product & & \\
6minute walk test & $403.06 \pm 110.87(I 20-670)$ & $429.33 \pm 107.35(283-620)$ \\
Bode index & $2(0-8)$ & $1(1-2)$ \\
Median (Range) & &
\end{tabular}

Table 3 Characteristics of demographic and quantitative CXR parameters of cases and controls

\begin{tabular}{llll}
\hline Parameters & Cases & Controls & p Value \\
\hline Age & $50.5 \pm 15.36(9-87)$ & $49.68 \pm 14.78(9-78)$ & 0 \\
Height & $163.44 \pm 9.06(134-192)$ & $161.85 \pm 9.23(125-180)$ & 0.38 \\
Weight & $60.29 \pm 12.74(26-110)$ & $54.17 \pm 11.77(19-85)$ & 0.006 \\
Ht Rt diaphragm [VP]] & $22.1 \pm 7.2(1.7-42)$ & $22.6 \pm 7.48(9.7-47)$ & 0.013 \\
HtRt diaphragm [CPJ] & $16.53 \pm 6.38(.01-31)$ & $16.32 \pm 7.29(1-53)$ & 0 \\
Ht Lt diaphragm [VPJ] & $19.99 \pm 6.38(1.7-39)$ & $19.53 \pm 6.18(7.4-34.1)$ & 0 \\
Height of right lung & $20.73 \pm 2.65(13.4-27.6)$ & $21.31 \pm 2.48(13.8-28.5)$ & 0 \\
No. of anterior ribs & $6.75 \pm 0.75(5-9)$ & $6.92 \pm 0.84(4-8)$ & 0.182 \\
No. of anterior ribs & $8.46 \pm 0.86(6-10)$ & $8.29 \pm 0.92(5-10)$ & 0.505 \\
No. of posterior ribs & $9.78 \pm 0.69(8-12)$ & $9.75 \pm 0.65(8-11)$ & 0.002 \\
Cardiothoracic ratio & $0.44 \pm 0.07(0.31-1)$ & $0.44 \pm 0.65(0.33-0.59)$ & 0.111 \\
Ratio of transverse diameter of trachea & $1.03 \pm 0.25(0.00-1.98)$ & $1.06 \pm 0.18(0.77-1.76)$ & 0.3 \\
\hline
\end{tabular}


Independent samples $\mathrm{T}$ test (at 5\% level of significance) was performed between the various qualitative parameters and PFT as given in Table 4. For certain parameters, $p$ values as obtained using One way ANOVA test, Mann-Whitney test and Kruskall- Wallis test. Alteration in vasculature in both upper and lower parts in both lung shows significant correlation with pulmonary function test including diffusion lung capacity variables [except TLC]. Alteration in vasculature in lower parts in both lungs showed significant correlation with BODE index. Presence of prominent intercostal slips showed significant correlation with spirometry, exercise capacity factors and BODE index. .Presence of increased lucency with intervening normal lucency of lung fields and presence of bulla showed significant correlation with spirometric indices. No significant correlation was found between the visualisation of the anterior junction line, posterior junction line and PFT, however visualisation of posterior junction line alone showed significant correlation with BODE index.

Pearson's correlation coefficient was calculated between the quantitative parameters and PFT as given in Table 5. Spearman's rank correlation was used in a few of the parameters. Vertebrophrenic junction as medial end point was not appreciated in 83 patients on the right side and 3 patients on the left side, similarly cardiophrenic junction as the medial point could not be clearly delineated in 13 patients. There was significant positive correlation between the height of right and left hemidiaphragm with various parameters of pulmonary function test (excluding DLCO, DLCO/Va) and exercise capacity factors. Height of left hemidiaphragm alone showed correlation with BODE index. Height of the right lung showed moderate negative correlation with most of spirometric indices and total lung capacity. Weak negative correlation was noted between cardiothoracic ratio, the level of diaphragm expressed as the number of posterior ribs with most of the spirometric indices. The level of diaphragm expressed as the number of anterior ribs in the lateral aspect showed weak positive correlation with FVC, which was not expected. Significant negative correlation was observed between the cardiothoracic ratio and total lung capacity. Significant negative correlation was observed between the level of diaphragm expressed as the number of posterior ribs and distance saturation product and 6 minute walk distance.

One-way ANOVA was used to assess the correlation of GOLD staging of cases with height of diaphragm and height of lung. It is found that there is a decrement of height of right and left hemidiaphragm as the severity of GOLD classification increases. However, the decrement is not statistically significant at 5\% level of significance for the parameters of height of right hemidiaphragm, but it is statistically significant for the parameters of left hemidiaphragm height. Although there is an increasing trend in height of lung as the severity increases, it is not statistically significant (Table 6). The correlation of qualitative and quantitative parameters with spirometry, BODE index and exercise capacity tests is summarised in Table 7.

Table 4 Correlation between qualitative parameters of CXR with PFT, exercise capacity factors \& BODE index

\begin{tabular}{|c|c|c|c|c|c|c|c|c|c|c|c|c|}
\hline Variables & $\begin{array}{l}\text { Post } \\
\text { FVC }\end{array}$ & $\begin{array}{l}\text { Post } \\
\text { FEV I }\end{array}$ & $\begin{array}{l}\text { \%Post } \\
\text { FEVI/FVC } \\
\text { Ratio }\end{array}$ & Post PEF & $\begin{array}{l}\text { Post } \\
\text { MMEF }\end{array}$ & $\begin{array}{l}\text { DLCo } \\
\text { Actual }\end{array}$ & $\begin{array}{l}\text { DLCI } \\
\text { VA }\end{array}$ & TLC & $\begin{array}{l}\text { RVI } \\
\text { TLC }\end{array}$ & $\begin{array}{l}\text { Dist. } \\
\text { Saturat } \\
\text { Product }\end{array}$ & $\begin{array}{l}\text { 6mi Walk } \\
\text { Test }\end{array}$ & $\begin{array}{l}\text { BODE } \\
\text { Index }\end{array}$ \\
\hline Sex & $<0.001$ & $<0.001$ & 0.538 & $<0.00 \mathrm{la}$ & 0.794 & 0.235 & 0.596 & - & - & 0.159 & 0.179 & - \\
\hline Smoking & 0.004 & 0.683 & $0.131 \mathrm{a}$ & 0.683 & 0.026 & 0.512 & 0.515 & 0.452 & 0.136 & 0.969 & 0.952 & - \\
\hline Prom. slips & 0.049 & $<0.001$ & $<0.001 \mathrm{a}$ & $<0.001$ & $<0.001$ & $<0.001$ & 0.004 & 0.338 & 0.689 & 0.106 & 0.137 & 0.011 \\
\hline Vas alt RTUP & 0.052 & 0.001 & $<0.001 \mathrm{a}$ & 0.001 & $<0.001$ & $0.014 a$ & 0.045 & 0.118 & 0.009 & 0.383 & 0.519 & 0.957 \\
\hline Vas alt RTLP & 0.001 & $<0.001$ & $<0.001$ & $<0.001$ & $<0.001$ & $0.019 a$ & 0.059 & 0.089 & 0.001 & 0.014 & 0.017 & 0.035 \\
\hline Vas alt LTUP & 0.006 & 0.001 & $<0.001$ & 0.001 & $<0.001$ & $0.014 a$ & 0.045 & 0.091 & 0.007 & 0.227 & 0.369 & 0.763 \\
\hline Vas alt LTLP & $<0.001$ & $<0.001$ & $<0.001$ & $<0.001$ & $<0.001$ & $0.005 a$ & 0.009 & 0.239 & 0.006 & 0.018 & 0.031 & 0.045 \\
\hline AJL & 0.971 & 0.568 & 0.733 & 0.568 & $0.86 I$ & 0.653 & 0.981 & 0.989 & 0.125 & 0.051 & 0.059 & 0.587 \\
\hline PJL & 0.924 & 0.988 & 0.208 & 0.988 & 0.53 & 0.379 & 0.659 & 0.745 & 0.287 & 0.656 & 0.654 & 0.039 \\
\hline BULLAE & 0.05 & 0.002 & $<0.00 \mathrm{la}$ & 0.002 & $<0.001$ & - & - & $0.453 a$ & 0.087 & $0.719 a$ & $0.47 \mathrm{la}$ & - \\
\hline Inc. lucency† & 0.417 & $<0.001$ & $<0.00 \mathrm{lb}$ & $<0.001$ & $<0.001 \mathrm{~b}$ & 0.553 & $0.243 b$ & 0.865 & $0.772 b$ & 0.828 & 0.978 & $0.923 b$ \\
\hline
\end{tabular}

Table 5 Correlation between quantitative parameters of CXR with PFT, exercise capacity factors \& BODE index

\begin{tabular}{|c|c|c|c|c|c|c|c|c|c|c|c|c|c|}
\hline & & $\begin{array}{l}\text { Post } \\
\text { FVC }\end{array}$ & $\begin{array}{l}\text { Post } \\
\text { FEVI }\end{array}$ & $\begin{array}{l}\% \text { Post } \\
\text { FEVI/FVC } \\
\text { Ratio\# }\end{array}$ & $\begin{array}{l}\text { Post } \\
\text { PEF\# }\end{array}$ & $\begin{array}{l}\text { Post } \\
\text { MMEF\# }\end{array}$ & DLCo & $\begin{array}{l}\text { DLCo/ } \\
\text { VA }\end{array}$ & TLC & $\begin{array}{l}\text { RVI } \\
\text { TLC \% } \\
\text { Pred }\end{array}$ & $\begin{array}{l}\text { Dist. } \\
\text { Saturat. } \\
\text { Product }\end{array}$ & $\begin{array}{l}\text { 6min } \\
\text { Walk } \\
\text { Test }\end{array}$ & $\begin{array}{l}\text { BODE } \\
\text { Index }\end{array}$ \\
\hline \multirow[t]{2}{*}{ RTVP } & $r$ & 0.306 & 0.364 & 0.384 & 0.353 & 0.353 & 0.341 & 0.203 & 0.463 & -0.385 & 0.444 & 0.432 & -0.558 \\
\hline & P-value & $<0.001$ & $<0.001$ & $<0.001$ & $<0.001$ & $<0.001$ & 0.095 & 0.33 & 0.013 & 0.043 & 0.012 & 0.015 & 0.059 \\
\hline \multirow[t]{2}{*}{ RTCP } & $r$ & 0.212 & 0.289 & 0.409 & 0.355 & 0.355 & 0.267 & 0.135 & 0.313 & -0.48 & 0.399 & 0.386 & -0.34 \\
\hline & $\mathrm{P}$-value & 0.002 & $<0.001$ & $<0.001$ & $<0.001$ & $<0.001$ & 0.087 & 0.395 & 0.031 & 0.001 & 0.01 & 0.012 & 0.216 \\
\hline \multirow[t]{2}{*}{ LTVP } & $r$ & 0.316 & 0.372 & 0.413 & 0.444 & 0.444 & 0.381 & 0.327 & 0.311 & -0.335 & 0.372 & 0.373 & -0.634 \\
\hline & $\mathrm{P}$-value & $<0.001$ & $<0.001$ & $<0.001$ & $<0.001$ & $<0.001$ & 0.011 & 0.03 & 0.03 & 0.019 & 0.012 & 0.011 & 0.005 \\
\hline \multirow[t]{2}{*}{$\begin{array}{l}\mathrm{Ht} \\
\text { LUNG }\end{array}$} & $r$ & 0.056 & -0.189 & -0.155 & -0.25 & -0.25 & -0.172 & -0.11 & 0.314 & 0.025 & -0.206 & -0.184 & 0.305 \\
\hline & $\mathrm{P}$-value & 0.412 & 0.005 & 0.023 & $<0.001$ & $<0.001$ & 0.271 & 0.482 & 0.03 & 0.867 & 0.179 & 0.227 & 0.235 \\
\hline
\end{tabular}


Table Continues...

\begin{tabular}{|c|c|c|c|c|c|c|c|c|c|c|c|c|c|}
\hline & & $\begin{array}{l}\text { Post } \\
\text { FVC }\end{array}$ & $\begin{array}{l}\text { Post } \\
\text { FEVI }\end{array}$ & $\begin{array}{l}\text { \%Post } \\
\text { FEVI/FVC } \\
\text { Ratio\# }\end{array}$ & $\begin{array}{l}\text { Post } \\
\text { PEF\# }\end{array}$ & $\begin{array}{l}\text { Post } \\
\text { MMEF\# }\end{array}$ & DLCo & $\begin{array}{l}\text { DLCo/ } \\
\text { VA }\end{array}$ & TLC & $\begin{array}{l}\text { RV/ } \\
\text { TLC \% } \\
\text { Pred }\end{array}$ & $\begin{array}{l}\text { Dist. } \\
\text { Saturat. } \\
\text { Product }\end{array}$ & $\begin{array}{l}\text { 6min } \\
\text { Walk } \\
\text { Test }\end{array}$ & $\begin{array}{l}\text { BODE } \\
\text { Index }\end{array}$ \\
\hline \multirow[t]{2}{*}{$\begin{array}{l}\text { ANT } \\
\text { MID }\end{array}$} & $r$ & 0.117 & -0.024 & 0.013 & -0.042 & -0.042 & -0.09 & 0.112 & 0.179 & -0.167 & 0.066 & 0.099 & 0.12 \\
\hline & $\mathrm{P}$-value & 0.087 & 0.727 & 0.847 & 0.535 & 0.535 & 0.562 & 0.469 & 0.219 & 0.251 & 0.671 & 0.517 & 0.646 \\
\hline \multirow[t]{2}{*}{ ANLAT } & $r$ & 0.169 & -0.022 & 0.016 & -0.016 & -0.016 & -0.103 & 0.094 & 0.166 & -0.12 & 0.049 & 0.06 & 0.125 \\
\hline & $\mathrm{P}$-value & 0.013 & 0.749 & 0.817 & 0.819 & 0.819 & 0.505 & 0.546 & 0.254 & 0.412 & 0.753 & 0.695 & 0.633 \\
\hline \multirow[t]{2}{*}{ POST } & $r$ & -0.018 & -0.131 & -0.149 & -0.196 & -0.196 & -0.263 & -0.202 & -0.082 & 0.032 & -0.328 & -0.306 & 0.282 \\
\hline & $\mathrm{P}$-value & 0.795 & 0.053 & 0.028 & 0.004 & 0.004 & 0.085 & 0.188 & 0.577 & 0.826 & 0.03 & $0.04 I$ & 0.273 \\
\hline \multirow[t]{2}{*}{ CTR } & $r$ & -0.174 & -0.108 & -0.172 & -0.179 & -0.179 & -0.141 & -0.089 & -0.533 & -0.037 & -0.187 & -0.18 & 0.097 \\
\hline & $\mathrm{P}$-value & 0.01 & 0.112 & 0.011 & 0.008 & 0.008 & 0.362 & 0.565 & $<0.001$ & 0.801 & 0.219 & 0.23 & 0.701 \\
\hline \multirow[t]{2}{*}{$\begin{array}{l}\text { COR } \\
\text { DIA }\end{array}$} & $r$ & 0.135 & -0.029 & -0.008 & -0.1 & -0.1 & 0.034 & 0.015 & 0.117 & 0.141 & 0.014 & 0.039 & 0.245 \\
\hline & $\mathrm{P}$-value & 0.051 & 0.664 & 0.906 & 0.145 & 0.145 & 0.826 & 0.924 & 0.424 & 0.334 & 0.93 & 0.802 & 0.327 \\
\hline
\end{tabular}

Table 6 Correlation of height of lung and height of diaphragm with GOLD stages of cases

\begin{tabular}{llllll}
\hline Parameters & \multicolumn{2}{l}{ Gold Staging of Cases } & \multicolumn{1}{c}{ p-Value } \\
\hline & Mild Mean (SD) & Moderate Mean (SD) & Severe Mean (SD) & Very Severe Mean (SD) \\
RTVP & $23.28(7.54)$ & $22.12(6.93)$ & $19.99(8.72)$ & $16.15(6.62)$ & 0.059 \\
RTCP & $17.00(5.39)$ & $16.02(6.08)$ & $13.88(5.52)$ & $13.43(10.96)$ & 0.137 \\
LTVP & $20.11(5.63)$ & $18.95(6.42)$ & $17.74(6.20)$ & $14.20(5.65)$ & 0.005 \\
HT LUNG & $21.33(2.89)$ & $21.40(2.5 \mathrm{I})$ & $21.64(2.44)$ & $22.02(1.88)$ & 0.748
\end{tabular}

Table 7 Correlation of qualitative and quantitative parameters with PFT, BODE index and exercise capacity tests

\begin{tabular}{|c|c|c|c|}
\hline & Positive Correlation & Negative Correlation & No Correlation \\
\hline \multirow[t]{8}{*}{ Spirometry } & \multicolumn{2}{|l|}{ Qualitative } & Qualitative \\
\hline & \multicolumn{2}{|l|}{ Alteration of vascular pattern } & Visualisation of anterior junction line \\
\hline & \multicolumn{2}{|l|}{ Prominent intercostal muscle slips } & Visualisation of posterior junction line \\
\hline & \multicolumn{3}{|l|}{ Increased lucency Presence of bulla } \\
\hline & Quantitative & Quantitative & Quantitative \\
\hline & \multirow[t]{3}{*}{ Height of right \& left hemidiaphragm } & Height of right lung & Ratio of coronal \\
\hline & & No: of posterior ribs & Diameter of trachea \\
\hline & & Cardiothoracic ratio & No: of anterior ribs \\
\hline BODE Index (*), & \multicolumn{2}{|l|}{ Qualitative } & Increased lucency \\
\hline 6 minute walk test [6MWT] & \multicolumn{2}{|c|}{$\begin{array}{l}\text { Alteration of vascular pattern in lower parts Prominent intercostal muscle } \\
\text { slips }(*)\end{array}$} & Presence of bulla \\
\hline \multirow[t]{6}{*}{ Distance saturation product [DSP] } & \multicolumn{2}{|c|}{ Visualisation of posterior junction line $(*)$} & Visualisation of anterior junction line \\
\hline & Quantitative & No: of posterior ribs [6MWT, DSP] & Height of right lung \\
\hline & \multicolumn{2}{|l|}{ Height of right \& left hemidiaphragm } & No: of anterior ribs \\
\hline & & & Cardiothoracic ratio \\
\hline & & & Ratio of transverse \\
\hline & & & Diameter of trachea \\
\hline
\end{tabular}

Using ROC analysis, for the population included in this study, the threshold value for height of lung indicating hyperinflation was $20.35 \mathrm{~cm}$ which has a sensitivity of $70 \%$ and specificity of $58 \%$. A value above $27.05 \mathrm{~cm}$ was found to have a specificity of $100 \%$ among the cases. The other quantitative parameters like the number of ribs seen anteriorly and posteriorly in CXR were not expected to be different between the Indian and Western population as difference in number of ribs is not expected between them. Cardiothoracic ratio also is not expected to be different as it is a ratio and not absolute values. 


\section{Discussion}

The present study differs from the previous studies in the objectives achieved as well as in the methodology. We have evaluated only the posteroanterior chest radiograph as lateral chest radiograph is not routinely done in our institution. Other studies have assessed lateral radiograph as well. ${ }^{8-10}$ Previous studies have considered the height of the hemidiaphragm ${ }^{9,10}$ as a subjective parameter. In the present study we have assessed the actual values, separately considering CPJ and VPJ as medial end points. The correlation is mildly better with vertebrophrenic junction being the medial end point, hence should be used instead of cardiophrenic junction, whenever it is visualised clearly. Assessing the number of ribs anteriorly at two points was newly introduced, the level of diaphragm measured in the anterolateral aspect showed correlation with FVC. Thurlbeck ${ }^{8}$ observed that level of the diaphragm measured anteriorly was one of the discriminating measurement for emphysema, the other being lung length. In our study, the level of diaphragm assessed in relation to the number of posterior rib showed correlation with most of the spirometric indices.

Instead of tracheal index, ${ }^{11}$ we used ratio of tracheal transverse diameter at two levels. However this did not show any correlation with spirometry or with BODE index. Visualisation of prominent intercostal slips was not included in any of the previous studies as diagnostic criteria ${ }^{11}$ and this showed significant correlation with PFT and BODE index. We have included other parameters like visualisation of anterior junctional line and posterior junctional line among the qualitative parameters, which were not assessed in previous studies. However, these had no significant correlation with spirometry. This could be related to better visualisation of the anterior junctional line and posterior junctional line even in normal individuals, with the use of digital radiography.

There are no similar studies in the literature done in the Indian population. This is important as the parameters of hyperinflation applicable for Western population may not be the same in Indian population due to variation in the body habitus. For the population included in this study, the threshold value for height of lung indicating hyperinflation is $20.35 \mathrm{~cm}$ whereas the western literature states height of lung more than $29.9 \mathrm{~cm}$ as one of the diagnostic criteria for lung hyperinflation. ${ }^{12}$ There are no studies available in the literature correlating chest radiographic indices with BODE index in the prognostication of COPD patient.

\section{Conclusion}

We observed that among the CXR parameters like flattening of hemidiaphragm, increase in the height of lung, no: of posterior ribs, cardiothoracic ratio, alteration of vascular pattern, presence of prominent intercostal slips, increased radiolucency, visualisation of posterior junction line and presence of bullae showed significant correlation with PFT and/or exercise capacity and BODE index. Thus by using both quantitative and qualitative parameters in CXR, we can predict the presence, severity and prognosis of COPD. Derived threshold values for parameters like height of lung in South Asian population are found to be lower than the Western population.

\section{Acknowledgments}

None.

\section{Conflicts of interest}

None.

\section{Funding}

None.

\section{References}

1. Jindal SK. Emergence of chronic obstructive pulmonary disease as an epidemic in India. Indian J Med Res. 2006; 124(6): 619-630.

2. Celi BR, Cote CG, Marin JM, et al. The body - mass index, airflow obstruction, dyspnea, and exercise capacity index in chronic obstructive pulmonary disease. $N$ Engl J Med. 2004;350(10):1005-1012.

3. Ong KC, Earnest A, Lu SJ. A multidimensional grading system (BODE index) as predictor of hospitalization for COPD. Chest. 2005;128(6):3810 3816.

4. Kilburn KH, Warshaw RH, Thornton JC. Do radiographic criteria for emphysema predict physiologic impairment? Chest. 1995;107(5):12251231

5. Pratt PC. Role of conventional chest radiography in diagnosis and exclusion of emphysema. Am J Med. 1987;82(5):998-1006.

6. Calverley PM. The GOLD classification has advanced understanding of COPD. Am J Respir Crit Care Med. 2004;170(3):211-212.

7. Screaton NJ. Emphysema and smoking-related lung disease. Imaging. 2004;16(1):50-60.

8. Thurlbeck WM, Simon G. Radiographic appearance of the chest in emphysema. AJR Am J Roentgenol. 1978;130(3):429-440.

9. Miniati M, Monti S, Stolk J, et al. Value of chest radiography in phenotyping chronic obstructive pulmonary disease. Eur Respir J. 2008;31(3):509-515.

10. Sutinen S, Christoforidis AJ, Klugh GA, et al. Roentgenologic criteria for the recognition of nonsymptomatic pulmonary emphysema. Correlation between roentgenologic findings and pulmonary pathology. Am Rev Respir Dis. 1965;91:69-76.

11. Nicklaus TM, Stowell DW, Christiansen WR, et al. The accuracy of the roentgenologic diagnosis of chronic pulmonary emphysema. Am Rev Respir Dis. 1966;93(6):889-899.

12. Reich SB, Weinshelbaum A, Yee J. Correlation of radiographic measurements and pulmonary function tests in chronic obstructive pulmonary disease. AJR Am J Roentgenol. 1985;144(4):695-699. 